JAMP: Jurnal Adminitrasi dan Manajemen Pendidikan Volume 1 Nomor 3 September 2018, Hal : 364-371

Tersedia Online di http://journal2.um.ac.id/index.php/jamp/ ISSN 2615-8574 (online)

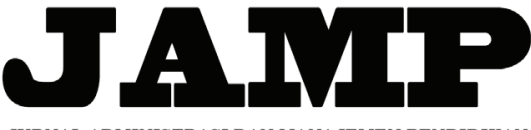

JURNAL ADMINISTRASI DAN MANAJEMEN PENDIDIKAN

\title{
PERSEPSI DAN SIKAP SISWA TENTANG KEGIATAN EKSTRAKURIKULER PRAMUKA
}

\author{
Pungki Randha Krisna \\ Mustiningsih2 \\ Desi Eri Kusumaningrum \\ E-mail: pungkimatic@gmail.com \\ Universitas Negeri Malang, Jalan Semarang 5 Malang 65145
}

\begin{abstract}
The purpose of this study: (1) to describe the level of student perceptions about scout extracurricular activities; (2) to describe students' attitudes towards scout extracurricular activities; and (3) to examine the relationship between perceptions and attitudes of students regarding scout extracurricular activities. This research is included in the quantitative descriptive research with the Dwivariate Correlational research model. Data was collected using a questionnaire obtained from 4 state high schools located in the urban center of Bojonegoro district. The results of this research and development are: (1) Students' perceptions of the Scout extracurricular activities in State High Schools throughout the Bojonegoro District are in the Good category; (2) Students' attitudes about Scouting extracurricular activities in State High Schools throughout Bojonegoro District are in the Good category; and (3) The relationship between student perception variables and attitude variables related to the Scout extracurricular activities shows that a positive correlation in the State Senior High Schools in Bojonegoro Subdistrict.
\end{abstract}

Keywords: student perceptions, student attitudes, scout extracurricular activities.

\begin{abstract}
Abstrak: : Penelitian ini bertujuan, untuk: (1) mendeskripsikan tingkat persepsi siswa tentang kegiatan ekstrakurikuler pramuka; (2) mendeskripsikan sikap siswa terhadap kegiatan ekstrakurikuler pramuka; dan (3) menguji hubungan persepsi dan sikap siswa tentang kegiatan ekstrakurikuler pramuka. Penelitian ini termasuk dalam jenis penelitian Deskriptif Kuantitatif dengan model penelitian Korelasional Dwivariat. Data dikumpulkan dengan menggunakan angket yang diperoleh dari dari 4 SMA Negeri yang terletak di pusat perkotaan Kabupaten Bojonegoro. Hasil penelitian ini menunjukkan, bahwa: (1) Siswa SMAN di Kecamatan Bojonegoro memiliki tingkat persepsi baik tentang kegiatan ekstrakurikuler Pramuka; (2) Siswa SMAN di Kecamatan Bojonegoro memiliki sikap baik tentang kegiatan ekstrakurikuler Pramuka; dan (3) Ada hubungan positif antara persepsi dan sikap tentang kegiatan ekstrakurikuler Pramuka di SMA Negeri se-Kecamatan Bojonegoro.
\end{abstract}

Kata kunci: persepsi, sikap, kegiatan ekstrakurikuler pramuka.

Dunia Pendidikan yang saat ini semakin berkembang pramuka menjadi salah satu faktor penting untuk pembentukan karakter Peserta Didik, Di Sekolah Dasar (SD) dan Sekolah Menengah Pertama (SMP) kegiatan pramuka menjadi salah satu ekstrakurikuler, anggotanya pun masih banyak. Namun sayangnya, keberadaan Pramuka di Sekolah Menengah Atas (SMA) nampaknya mulai meredup dan sedikit sekali anggotanya. Berdasarkan fakta tersebut diasumsikan ada kendala dalam pelaksanaan kegiatan Pramuka di sekolah menengah atas saat ini. Pembaruan riset terkait kepramukaan ini perlu dilakukan karena pendidikan kepramukaan memiliki peranan penting dalam pendidikan karakter siswa. 
Dalam penelitian yang dilakukan oleh Portnov-Neeman dan Barak (2013) menunjukkan bahwa persepsi terhadap kegiatan kepramukaan di kalangan remaja khususnya siswa Sekolah Menengah Atas tergolong menurun dibandingkan dengan persepsi mereka terkait kegiatan kepramukaan pada jenjang sekolah yang lebih rendah. Siwa beranggapan bahwa keikutsertaan dalam kegiatan pramuka itu tidak lagi sesuai dengan porsi pendidikan mereka. Karena kegiatan ekstrakurikuler pramuka dianggap kekanakkanakan dan kurang bermanfaat. Gejala rendahnya minat siswa dalam kegiatan ekstrakurikuler pramuka ditunjukkan dengan tingkat kehadiran siswa yang tidak hadir dalam kegiatan pramuka, siswa yang tidak serius dalam mengikuti kegiatan ekstrakurikuler pramuka dan siswa tidak melaksanakan tugas dengan baik selama mengikuti kegiatan ekstrakurikuler pramuka.

Fakta lain dalam penelitian Portnov-Neeman dan Barak (2013) menunjukkan bahwa kegiatan kepramukaan jauh kalah populer dibanding dengan kelompok pecinta alam. Perkembangan kegiatan kelompok pecinta alam sudah sedemikian pesatnya sehingga muncul aktivitas yang menarik bagi remaja seperti panjat tebing, caving, dan mountainering. Pada perkembangan yang sama sebagian besar satuan gerakan pramuka masih melakukan kegiatan alam terbuka dengan acara mencari jejak, permainan berbagai macam sandi, wide game yang dipandang oleh remaja terlalu monoton dan sudah kuno. Padahal dalam penelitian lain yang dilakukan leh Wilson (2009) disebutkan bahwa pramuka merupakan satu-satunya organisasi yang diakui negara dan mempunyai undang-undang. Dalam kegiatan pramuka metode pengajaran yang diajarkan di pramuka menggunakan konsep alam bebas dan petualangan, dimana anggotanya langsung berinteraksi dengan alam dan masyarakat sekitar. Konsep dasa darma dan tri satya menjadi pegangan mereka dan harus mencerminkan kedua hal tersebut. Jiwa kepemimpinan terus ditanamkan dalam jiwa anggota pramuka, kekompakkan dan keceriaan menjadi salah satu hal yang paling menonjol pada kegiatan tersebut.

Fakta lain dalam penelitian Portnov-Neeman dan Barak (2013) menunjukkan bahwa kegiatan kepramukaan jauh kalah populer dibanding dengan kelompok pecinta alam. Perkembangan kegiatan kelompok pecinta alam sudah sedemikian pesatnya sehingga muncul aktivitas yang menarik bagi remaja seperti panjat tebing, caving, dan mountainering. Pada perkembangan yang sama sebagian besar satuan gerakan pramuka masih melakukan kegiatan alam terbuka dengan acara mencari jejak, permainan berbagai macam sandi, wide game yang dipandang oleh remaja terlalu monoton dan sudah kuno. Padahal dalam penelitian lain yang dilakukan leh Wilson (2009) disebutkan bahwa pramuka merupakan satu-satunya organisasi yang diakui negara dan mempunyai undang-undang. Dalam kegiatan pramuka metode pengajaran yang diajarkan di pramuka menggunakan konsep alam bebas dan petualangan, dimana anggotanya langsung berinteraksi dengan alam dan masyarakat sekitar. Konsep dasa darma dan tri satya menjadi pegangan mereka dan harus mencerminkan kedua hal tersebut. Jiwa kepemimpinan terus ditanamkan dalam jiwa anggota pramuka, kekompakkan dan keceriaan menjadi salah satu hal yang paling menonjol pada kegiatan tersebut.

Berdasarkan hal tersebut, peneliti ingin meneliti lebih dalam tentang "Hubungan Antara Persepsi dan Sikap Siswa dalam Kegiatan Ekstrakurikuler Pramuka di SMA Negeri Se-Kecamatan Bojonegoro, Kabupaten Bojonegoro". Tujuan penelitian ini adalah (1) Mendeskripsikan tingkat persepsi siswa tentang kegiatan ekstrakurikuler pramuka; (2) Mendeskripsikan sikap siswa terhadap kegiatan ekstrakurikuler pramuka; dan (3) Menguji hubungan persepsi dan sikap siswa tentang kegiatan ekstrakurikuler pramuka.

\section{METODE}

Penelitian ini menggunakan penelitian Deskriptif Kuantitatif dengan model penelitian Korelasional Dwivariat. Model Korelasional Dwivariat yaitu model penelitian yang mengungkapkan hubungan asimetris variabel bebas (Independent Variable) dan variabel terikat (Dependent Variable). Data dikumpulkan dengan menggunakan angket yang diperoleh dari dari 4 SMA Negeri yang terletak di pusat perkotaan Kabupaten Bojonegoro.

Populasi dalam penelitian ini yaitu seluruh peserta didik kelas X di SMA Negeri Se-Kecamatan Bojonegoro, Kabupaten Bojonegoro, yaitu sebanyak 1.059 siswa. Adapun penarikan sampel dalam penelitian ini dilakukan dengan menggunakan teknik Random Sampling. Berdasarkan teknik pengambilan sampel tersebut, maka diperoleh sampel penelitian sejumlah 316 siswa. 
Analisis data dilakukan menggunakan dua teknik analisis yakni deskriptif dan metode analisis korelasi. Analisis deskriptif dalam penelitian ini dilakukan untuk menjawab tentang persepsi dan sikap siswa terahdap kegiatan ekstrakurikuler pramuka.

Sementara itu, analisis korelasi digunakan untuk mengetahui suatu hubungan antar variabel. Dalam penelitian ini menggunakan rumus Korelasi Spearman. Teknik ini digunakan untuk mengetahui besarnya hubungan antara persepsi dan sikap siswa terhadap kegiatan pramuka di Sekolah Menengah Atas negeri Se-Kecamatan Bojonegoro, Kabupaten Bojonegoro.

\section{HASIL}

\section{Analisis Deskriptif Variabel Penelitianv}

Berikut disajikan hasil deskripsi variabel penelitian meliputi Persepsi dan Sikap.

Tabel 1 Deskripsi Persepsi

\begin{tabular}{llrrrr}
\hline & Frequency & & Percent & Valid Percent & \multicolumn{2}{c}{$\begin{array}{c}\text { Cumulative } \\
\text { Percent }\end{array}$} \\
\hline \multirow{2}{*}{ Valid } & & & 0.1 & 100.0 \\
Rendah & 3 & 0,094936 & 2.5 & \\
Sedang & 8 & 2,531646 & 29.1 & \\
Tinggi & 91 & 29,11392 & 63.6 & \\
Sangat Tinggi & 201 & 63,60759 & 3.8 & \\
Total & 12 & 3,797468 & 100.0 & \\
\hline
\end{tabular}

Sumber : Data Penelitian Diolah (2018)

Hasil deskripsi Persepsi diperoleh 3 orang atau 0,1 persen memiliki persepsi yang sangat rendah, 8 orang atau 2,5 persen memiliki persepsi yang rendah, 91 orang atau 29,1 persen memiliki persepsi yang sedang, 201 orang atau 63,6 persen memiliki persepsi yang tinggi, dan 12 orang atau 3,8 persen memiliki persepsi yang sangat tinggi.

Tabel 2 Deskripsi Sikap

\begin{tabular}{llcrrr}
\hline & Frequency & & Percent & Valid Percent & \multicolumn{2}{c}{$\begin{array}{c}\text { Cumulative } \\
\text { Percent }\end{array}$} \\
\hline \multirow{2}{*}{ Valid } & Sangat Rendah & 6 & 0.316456 & 0.3 & 100.0 \\
Rendah & 15 & 4.746835 & 4.7 & \\
Sedang & 65 & 20.56962 & 20.6 & \\
Tinggi & 214 & 69,3038 & 69,3 & \\
Sangat Tinggi & 16 & 5,063291 & 5,1 & \\
Total & 316 & 100.0 & 100.0 & \\
\hline
\end{tabular}

Sumber : Data Penelitian Diolah (2018)

Hasil deskripsi sikap diperoleh 6 orang atau 0,3 persen memiliki sikap yang sangat kurang baik, 15 orang atau 4,7 persen memiliki sikap yang kurang baik, 65 orang atau 20,6 persen memiliki sikap yang sedang, 214 orang atau 69,3 persen memiliki sikap yang baik, dan 16 orang atau 5,1 persen memiliki sikap yang sangat baik.

\section{Hasil Uji Normalitas}

Berikut disajikan hasil uji normalitas variabel penelitian meliputi Persepsi dan Sikap. 
Tabel 3 Hasil Uji Normalitas

\begin{tabular}{lcc}
\hline & Persepsi & Sikap \\
\hline Kolmogorov-Smirnov Z & 2.338 & 3.731 \\
Asymp. Sig. (2-tailed) & .000 & .000 \\
\hline
\end{tabular}

Sumber : Data Penelitian Diolah (2018)

Hasil uji normalitas Persepsi dan Sikap diperoleh nilai signifikansi kedua variabel kurang dari 0,05 sehingga kedua data tidak mengikuti sebaran normal.

\section{Hasil Analisis Korelasi Spearman}

Dalam penelitian ini analisis statistik digunakan untuk mencaritahu fokus penelitian ini yakni bagaimana hubungan persepsi dan sikap siswa tentang kegiatan ekstrakurikuler pramuka. Adapun rumus yang digunakan dalam mennganalisis hubungan dua variabel yang diteliti tersebut digunakan rumus uji Korelasi Spearman. Berikut disajikan hasil uji hubungan antara variabel penelitian meliputi Persepsi dan Sikap dengan menggunakan uji korelasi Spearman.

Tabel 4 Hasil Uji Korelasi Spearman

\begin{tabular}{lllll}
\hline & & Persepsi & Sikap \\
\hline Spearman's rho & Persepsi & Correlation Coefficient & 1.000 & $.263^{* *}$ \\
& & Sig. (2-tailed) &. & .000 \\
& N & 316 & 316 \\
& Sikap & Correlation Coefficient & $.263^{* *}$ & 1.000 \\
& & Sig. (2-tailed) & .000 &. \\
& N & 316 & 316 \\
\hline
\end{tabular}

Sumber : Data Penelitian Diolah (2018)

Hasil uji korelasi Spearman antara Persepsi dan Sikap diperoleh nilai koefisien korelasi sebesar 0,263 dan signifikansi 0,000 . Hal ini menunjkkan adanya korelasi positif $(r>0)$ dan signifikan $(p<0,05)$ artinya bahwa semakin tinggi persepsi siswa maka sikap yang dilakukan semakin baik pula.

\section{PEMBAHASAN}

\section{Tingkat Persepsi Siswa Tentang Kegiatan Ekstrakurikuler Pramuka}

Berdasarkan hasil analisis dalam penelitian ini diketahui bahwa tingkat persepsi siswa tentang kegiatan ekstrakurikuler Pramuka di SMA Negeri Se-Kecamatan Bojonegoro, Kabupaten Bojonegoro termasuk dalam kategori Baik. Hal ini ditunjukkan dengan hasil deskripsi Persepsi diperoleh 13 orang atau 4,1 persen memiliki persepsi yang rendah dan 303 orang atau 95,9 persen memiliki persepsi yang tinggi.

Temuan tersebut menunjukkan bahwa penyelenggaraan kegiatan ekstrakurikuler Pramuka di SMA Negeri Se-Kecamatan Bojonegoro, Kabupaten Bojonegoro menunjukkan fungsinya sesuai dengan tujuan penyelenggaraan pendidikan kepramukaan. Hal ini sesuai dengan teori yang menyatakan bahwa gerakan pramuka berfungsi sebagai wadah pembinaan dan pengembangan generasi muda Indonesia tentunya mempunyai tugas pokok untuk menyelenggarakan kepramukaan bagi kaum muda guna menumbuhkan tunas bangsa agar menjadi generasi yang lebih baik, bertanggung jawab, mampu mengisi kemerdekaan nasional dan membangun dunia yang lebih baik. Dalam melaksanakan tugas pokoknya gerakan pramuka atau kegiatan pramuka memerlukan suatu perencanaan dan program yang strategik dan berkesinambungan berupa kebijakan dan prioritas program yang dituangkan dalam Rencana Kegiatan Gerakan Pramuka agar tujuan yang ingin dicapai dapat terlaksana sebagaimana mestinya (Kwartir Nasional Gerakan Pramuka, 2010:3-4). 
Berdasarkan hasil wawancara kepada bagian kesiswaan masing-masing sekolah sampel diketahui bahwa pelaksanaan pendidikan kepramukaan di di SMA Negeri Se-Kecamatan Bojonegoro, Kabupaten Bojonegoro saat ini berbeda dengan pelaksanaan pendidikan kepramukaan pada umumnya yang bersifat pendidikan luar sekolah. Adapun pelaksanaan pendidikan kepramukaan di di SMA Negeri SeKecamatan Bojonegoro, Kabupaten Bojonegoro sudah mengalami beberapa adaptasi dan penyesuaian dengan kondisi kurikulum saat ini dan menyesuaikan dengan kondisi sekolah. Contoh nyata dari bentuk adaptasi tersebut diantaranya penetapan pendidikan kepramukaan sebagai mata pelajaran muatan lokal seperti yang terjadi di SMAN 4 Bojonegoro. Perubahan dari ekstrakulikuler menjadi mata pelajaran muatan lokal tersebut dilakukan guna mempertahankan eksistensi pendidikan kepramukaan di tengah padatnya jam pelajaran yang mengangkat kuriulm K13 dan full day school. Contoh lain adalah pelaksanaan pendidikan kepramukaan di Aula khusus seperti yang terjadi di SMAN 4 Bojonegoro dan SMAN 3 Bojonegoro guna menanggulangi kurangnya lahan sekolah untuk kegiatan ekstrakulikuler. Bentuk adaptasi tersebut diharapkan pelaksanaan pendidikan pramuka masih dapat dilakukan meskipun dihadapkan pada beberapa masalah seperti perubahan sistem belajar mengajar maupun keterbatasan sekolah.

Lebih lanjut penanaman persepsi dalam pembentukan karakter siswa melalui kegiatan ekstrakurikuler Pramuka di SMA Negeri Se-Kecamatan Bojonegoro, Kabupaten Bojonegoro juga menunjukkan nilai positif terutama melalui kegiatan kepramukaan yang selama ini dilakukan. Adapun dalam prosesnya, kegiatan ekstrakurikuler Pramuka di SMA Negeri Se-Kecamatan Bojonegoro, Kabupaten Bojonegoro sendiri diupayakan untuk tetap berada di dalam koridor pengajaran yang memegang teguh metode kepramukaan. Hal ini ditunjukkan dari adanya kegiatan pelatihan dan asah keterampilan seperti tali temali, baris berbaris, berpidato atau ceramah, kerja kelompok, ibadah, dan penjelajahan alam. Adapun kegiatan tersebut patut diberi apresiasi karena keterbatasan sekolah dan penerapan kurikulum 2013 serta sistem fullday school yang membatasi sekolah dalam menjalankan kegiatan kepramukaan.

Hal ini sesuai dengan teori bahwa metode kepramukaan pada hakekatnya tidak dapat dilepaskan dari Prinsip Dasar Kepramukaan. Keterkaitan itu terletak pada pelaksanaan Kode Kehormatan. Metode Kepramukaan sebagai suatu sistem, terdiri atas unsur-unsur yang merupakan subsistem terpadu dan terkait, yang tiap unsurnya mempunyai fungsi pendidikan yang spesifik dan saling memperkuat serta menunjang tercapainya tujuan. Adapun metode kepramukaan yang diterapkan di SMA Negeri SeKecamatan Bojonegoro, Kabupaten Bojonegoro juga sudah mencakup kegitan belajar interaktif progresif, pengembangan rohani dan jasmani, penanaman materi kegiatan di alam terbuka dan kemandirian.

Lebih lanjut penanaman persepsi dalam pembentukan karakter siswa melalui kegiatan ekstrakurikuler Pramuka di SMA Negeri Se-Kecamatan Bojonegoro, Kabupaten Bojonegoro juga menunjukkan nilai positif terutama melalui kegiatan kepramukaan yang selama ini dilakukan. Adapun dalam prosesnya, kegiatan ekstrakurikuler Pramuka di SMA Negeri Se-Kecamatan Bojonegoro, Kabupaten Bojonegoro sendiri diupayakan untuk tetap berada di dalam koridor pengajaran yang memegang teguh metode kepramukaan. Hal ini ditunjukkan dari adanya kegiatan pelatihan dan asah keterampilan seperti tali temali, baris berbaris, berpidato atau ceramah, kerja kelompok, ibadah, dan penjelajahan alam. Adapun kegiatan tersebut patut diberi apresiasi karena keterbatasan sekolah dan penerapan kurikulum 2013 serta sistem fullday school yang membatasi sekolah dalam menjalankan kegiatan kepramukaan.

Hal ini sesuai dengan teori bahwa metode kepramukaan pada hakekatnya tidak dapat dilepaskan dari Prinsip Dasar Kepramukaan. Keterkaitan itu terletak pada pelaksanaan Kode Kehormatan. Metode Kepramukaan sebagai suatu sistem, terdiri atas unsur-unsur yang merupakan subsistem terpadu dan terkait, yang tiap unsurnya mempunyai fungsi pendidikan yang spesifik dan saling memperkuat serta menunjang tercapainya tujuan. Adapun metode kepramukaan yang diterapkan di SMA Negeri SeKecamatan Bojonegoro, Kabupaten Bojonegoro juga sudah mencakup kegitan belajar interaktif progresif, pengembangan rohani dan jasmani, penanaman materi kegiatan di alam terbuka dan kemandirian.

\section{Tingkat Sikap Siswa Terhadap Kegiatan Ekstrakurikuler Pramuka}

Berdasarkan hasil analisis dalam penelitian ini diketahui bahwa tingkat sikap siswa tentang kegiatan ekstrakurikuler Pramuka di SMA Negeri Se-Kecamatan Bojonegoro, Kabupaten Bojonegoro termasuk 
dalam kategori Baik. Hal ini ditunjukkan dengan hasil deskripsi Sikap diperoleh 316 orang atau 100 persen memiliki sikap yang baik/tinggi.

Tingkatan sikap yang baik ini menunjukkan keberhasilan pencapaian tujuan dari kegiatan kepramukaan yang dilakukan oleh SMA Negeri Se-Kecamatan Bojonegoro, Kabupaten Bojonegoro. Adapun keberhasilan pembentukan sikap siswa yang disebabkan oleh keaktifnnya dalam kegiatan pramuka ini menunjukkan bahwa dalam diri siswa tertanam karakter dan akhlak yang baik yang menjadi tujuan dilakukannya kegiatan pramuka. Hal ini juga menunjukkan bahwa kegiatan kepramukaan telah berhasil menjadi kegiatan pembinaan karakter dan kepribadian yang ditujukan untuk mengembangkan potensi diri serta memiliki akhlak mulia, pengendalian diri, dan kecakapan kehidupan

Dengan demikian dapat dikatakan bahwa kegiatan ekstrakurikuler Pramuka di SMA Negeri Se-Kecamatan Bojonegoro, Kabupaten Bojonegoro telah berhasil memenuhi tujuan dilakukannya penyelenggaraan pendidikan kepramukaan. Hal ini sesuai dengan teori yang menyatakan bahwa penyelenggaraan gerakan pramuka di Indonesia memiliki beberapa maksud diantaranya yaitu:

1. sebagai wadah dan sarana pembangunan kepribadian yang ditujukan untuk mengembangkan potensi diri serta memiliki akhlak mulia, pengendalian diri, dan kecakapan kehidupan bagi setiap warga negara demi tercapainya kesejahteraan masyarakat.

2. sebagai wadah pengembangan potensi diri dalam pemenuhan hak asasi manusia yang diwujudkan dalam penyelenggaraan pendidikan, antara lain melalui gerakan pramuka.

3. bahwa gerakan pramuka selaku penyelenggara pendidikan kepramukaan mempunyai peran besar dalam pembentukan kepribadian generasi muda sehingga memiliki pengendalian dan kecakapan hidup untuk menghadapi tantangan sesuai dengan tuntutan perubahan kehidupan lokal, nasional, dan global. (Kwartir Nasional Gerakan Pramuka, 2010:1)

\section{Hubungan Persepsi Dan Sikap Siswa Tentang Kegiatan Ekstrakurikuler Pramuka}

Berdasarkan hasil analisis dalam penelitian ini diketahui bahwa hasil uji korelasi Spearman antara variable persepsi siswa dan variable sikap terkait kegiatan ekstrakurikuler Pramuka di SMA Negeri Se-Kecamatan Bojonegoro, Kabupaten Bojonegoro diperoleh nilai koefisien korelasi sebesar 0,263 dan signifikansi 0,000 . Hal ini menunjukkan adanya korelasi positif $(r>0)$ dan signifikan $(p<0,05)$ artinya bahwa semakin tinggi persepsi siswa maka sikap yang dilakukan semakin baik pula. Hasil tersebut menunjukkan bahwa variabel persepsi siswa memberikan pengaruh positif terhadap variabel sikap siswa tentang kegiatan ekstrakurikuler Pramuka di SMA Negeri Se-Kecamatan Bojonegoro, Kabupaten Bojonegoro.

Dalam pelaksanaan pendidikan kepramukaan di di SMA Negeri Se-Kecamatan Bojonegoro, Kabupaten Bojonegoro sendiri saat ini berbeda dengan pelaksanaan pendidikan kepramukaan pada umumnya yang bersifat pendidikan luar sekolah. Adapun pelaksanaan pendidikan kepramukaan di di SMA Negeri Se-Kecamatan Bojonegoro, Kabupaten Bojonegoro sudah mengalami beberapa adaptasi dan penyesuaian dengan kondisi kurikulum saat ini dan menyesuaikan dengan kondisi sekolah. Contoh penetapan pendidikan kepramukaan sebagai mata pelajaran muatan lokal hingga perubahan sistem pendidikan kepramukaan yang bersifat luar sekolah (outdoor) menjadi kegiatan indoor. Hal ini bertolak belakang dengan keterangan Kwartir Nasional Gerakan Pramuka (2010:6) yang menyatakan bahwa kegiatan kepramukaan adalah proses pendidikan lingkungan luar sekolah dan di luar keluarga dalam bentuk kegiatan menarik, menyenangkan, sehat, teratur, terarah, praktis yang dilakukan di alam terbuka dengan prinsip dasar pendidikan kepramukaan dan metode pendidikan kepramukaan yang sasaran akhirnya adalah pembentukan watak, akhlak, dan budi pekerti luhur. Selain itu, Kartini (2001:5) mendefinisikan bahwa kepramukaan merupakan proses pendidikan luar lingkungan sekolah dan di luar lingkungan keluarga dalam bentuk kegiatan menarik, menyenangkan, sehat, teratur, terarah, praktis, yang dilakukan di alam terbuka dengan prinsip dasar kepramukaan dan metode kepramukaan, yang sasaran akhirnya pembentukan watak.

Adapun dengan hasil positif yang ditunjukkan dari deskripsi persepsi siswa dan sikap siswa terkait kegiatan ekstrakurikuler Pramuka menunjukkan bahwa bentuk adaptasi dan penyesuaian proses 
pendidikan kepramukaan di SMA Negeri Se-Kecamatan Bojonegoro, Kabupaten Bojonegoro tidak memberikan dampak negatif terhadap proses dan hasil yang diperoleh. Di sisi lain, proses adaptasi dan penyesuaian kegiatan kepramukaan yang dilakukan di SMA Negeri Se-Kecamatan Bojonegoro, Kabupaten Bojonegoro ini dapat menjadi contoh penyelesaian masalah yang muncul dikarenakan perkembangan kurikulum dan pergantian sistem belajar full day yang diterapkan saat ini.

Pengembangan persepsi siswa melalui pendidikan kepramukaan yang baik dalam hal ini sesuai dengan tujuan dari gerakan pramuka sendiri yakni berfungsi sebagai wadah pembinaan dan pengembangan generasi muda Indonesia. Hal ini sesuai dengan teori tujuan dari gerakan pramuka yakni berfungsi sebagai wadah pembinaan dan pengembangan generasi muda Indonesia tentunya mempunyai tugas pokok untuk menyelenggarakan kepramukaan bagi kaum muda guna menumbuhkan tunas bangsa agar menjadi generasi yang lebih baik, bertanggung jawab, mampu mengisi kemerdekaan nasional dan membangun dunia yang lebih baik (Kwartir Nasional Gerakan Pramuka, 2010:3-4). Dalam melaksanakan tugas pokoknya gerakan pramuka atau kegiatan pramuka memerlukan suatu perencanaan dan program yang strategik dan berkesinambungan berupa kebijakan dan prioritas program yang dituangkan dalam Rencana Kegiatan Gerakan Pramuka agar tujuan yang ingin dicapai dapat terlaksana sebagaimana mestinya.

Hasil tersebut menunjukkan bahwa kegiatan ekstrakurikuler Pramuka di SMA Negeri Se-Kecamatan Bojonegoro, Kabupaten Bojonegoro dapat dikatakan berhasil dalam menyampaikan materi pendidikan kepramukaan dan mencapai tujuan dalam membentuk karakter dan akhlak peserta didik yang baik. Temuan ini sesuai dengan teori tujuan penyelenggaraan gerakan pramuka di Indonesia yakni sebagai wadah dan sarana pembangunan kepribadian yang ditujukan untuk mengembangkan potensi diri serta memiliki akhlak mulia, pengendalian diri, dan kecakapan kehidupan bagi setiap warga negara demi tercapainya kesejahteraan masyarakat (Kwartir Nasional Gerakan Pramuka, 2010:1). Adapun potensi diri serta memiliki akhlak mulia, pengendalian diri, dan kecakapan kehidupan dari tujuan tersebut dalam penelitian ini dapat dilihat dari variabel sikap yang positif yang muncul sebagai hasil dari pengembangan persepsi yang positif pula.

Secara keseluruhan temuan positif bahwa semakin tinggi persepsi siswa maka sikap yang dilakukan semakin baik pula menunjukkan bahwa pelaksanaan kegiatan ekstrakurikuler Pramuka di SMA Negeri Se-Kecamatan Bojonegoro, Kabupaten Bojonegoro dijalankan sesuai dengan fungsi sebagaimana mestinya dan mencapai tujuan yang sesuai dengan arah pendidikan kepramukaan itu sendiri. Tujuan kepramukaan sendiri secara khusus tertuang dalam dalam Undang-Undang No. 12 Tahun 2010 Tentang Kepramukaan Pasal 4 dijelaskan bahwa gerakan pramuka bertujuan untuk membentuk setiap anggota pramuka agar memiliki kepribadian yang beriman, bertakwa, berakhlak mulia, berjiwa patriotik, taat hukum, disiplin, menjunjung tinggi nilai-nilai luhur bangsa dan memilki kecakapan hidup sebagai kader bangsa dalam menjaga dan membangun Negara Kesatuan Republik Indonesia, mengamalkan Pancasila serta melestarikan lingkungan hidup.

Lebih lanjut berdasarkan hasil penyebaran kuesioner persepsi peserta didik dan sikap terkait kegiatan ekstrakurikuler Pramuka di SMA Negeri Se-Kecamatan Bojonegoro, Kabupaten Bojonegoro diketahui pula bahwa siswa yang mengikuti kegiatan pramuka memiliki pemahaman persepsi yang baik terkait materi Tri Satya dan Dasa Darma Pramuka serta memiliki motivasi yang positif untuk menerapkan pemahaman mereka tersebut dalam kehidupan sehari-hari. Hal ini sesuai dengan UU No. 12 Tahun 2010 tentang kepramukaan terutama terkait pemahaman dasar dari kegiatan pramuka yang bertujuan untuk membimbing siswa yang mengikuti kegiatan pramuka untuk mencapai nilai-nilai positif dari kegiatan pramuka tersebut.

Dalam Undang-Undang tersebut disebutkan bahwa seorang yang mengikuti kegiatan pramuka adalah warga negara Indonesia yang aktif dalam pendidikan kepramukaan serta mengamalkan Satya Pramuka dan Darma Pramuka. Satya dan Darma Pramuka merupakan kode kehormatan bagi tiaptiap siaga yang harus dihormati dan diamalkan. Dapat dipahami bahwa Satya dan Darma Pramuka merupakan hal dasar dari kegiatan pramuka yang bertujuan untuk membimbing siswa yang mengikuti kegiatan pramuka untuk mencapai nilai-nilai positif dari kegiatan tersebut (UU No. 12 Tahun 2010). 
Nilai-nilai ini merupakan nilai moral yang ada dalam perilaku anggota pramuka. Nilai-nilai kepramukaan bersumber dari Tri Satya, Dasa Dharma, kecakapan dan keterampilan yang dikuasai anggota pramuka. Kepramukaan yang tersirat itu adalah untuk membentuk karakter bagi anggotanya. Menurut Patimah (2011:10) secara umum nilai-nilai karakter yang tercantum dalam pembinaan kegiatan pramuka adalah percaya diri, patuh pada aturan-aturan sosial, menghargai keberagaman, berpikir logis, kritis, kreatif dan inovatif, mandiri, pemberani, bekerja keras, tekun, ulet/gigih, disiplin, visioner, bersahaja, bersemangat, dinamis, pengabdian, tertib, konstruktif.

\section{KESIMPULAN}

Berdasarkan hasil penelitian dan pembahasan pada bab sebelumnya maka dapat ditarik kesimpulan dalam penelitian ini adalah sebagai berikut.

1. Tingkat persepsi siswa tentang kegiatan ekstrakurikuler Pramuka di SMA Negeri Se-Kecamatan Bojonegoro, Kabupaten Bojonegoro termasuk dalam kategori Baik.

2. Berdasarkan hasil analisis dalam penelitian ini diketahui bahwa tingkat sikap siswa tentang kegiatan ekstrakurikuler Pramuka di SMA Negeri Se-Kecamatan Bojonegoro, Kabupaten Bojonegoro termasuk dalam kategori Sangat Baik.

3. Hubungan antara variabel persepsi siswa dan variabel sikap terkait kegiatan ekstrakurikuler Pramuka di SMA Negeri Se-Kecamatan Bojonegoro, Kabupaten Bojonegoro menunjukkan adanya korelasi Positif artinya bahwa semakin tinggi persepsi siswa maka sikap yang dilakukan semakin baik pula. Hasil tersebut menunjukkan bahwa variabel persepsi siswa memberikan pengaruh positif terhadap variabel sikap siswa tentang kegiatan ekstrakurikuler Pramuka di SMA Negeri Se-Kecamatan Bojonegoro, Kabupaten Bojonegoro.

\section{DAFTAR RUJUKAN}

Arikunto, Suharsimi. 2006. Metodelogi penelitian. Yogyakarta: Bina Aksara.

David, O'Keefe Sear., Freedman., Jonathan, Freedman., \& Letita. Anne Peplau. 1985. Psikologi Sosial: Edisi Kelima. Alih Bahasa Michael Adryanto. Jakarta: Penerbit Erlangga

Hanurawan, Fattah. 2007. Pengantar Psikologi Sosial. Malang: Fakultas Ilmu Pendidikan Universitas Negeri Malang.

Kartini, Harti. 2001. Petunjuk Membina Pramuka Golongan Siaga. Malang: Fakultas Ilmu Pendidikan Universitas Negri Malang.

Kwartir Nasional Gerakan Pramuka. 2010. Anggaran Dasar dan Anggaran Rumah Tangga Gerakan Pramuka. Jakarta : Pustaka Tunas Media

Portnov-Neeman, Yelena., dan Barak, Moshe. 2013. Exploring Students Perceptions about Learning in School: An Activity Theory Based Study. Journal Education and Learning: Vol 2, No 3; 2013, ISSN 1927-5250, E ISSN 1927-5269. Canadian Center odf Science and Education, Canada.

Setyadin, Bambang. 2005. Modul IV: Desain dan Metode Penelitian Kuantitatif. Malang: Lembaga Penelitian Universitas Negeri Malang.

Siagian, Sugiarto Dergibson., Lasmono, Tri Sunaryanto., \& Oetomo, Deny. 2003. Teknik sampling. Jakarta: PT SUN.

Sugiyono, 2009, Statistika Untuk Penelitian, Bandung: Alfabet

Sugiyono. 2003. Metode Penelitian Bisnis. Bandung. Pusat Bahasa Depdiknas

Tabrani, Sudirman. 1987. Ilmu Pendidikan. Bandung: Remaja Rosda Karya Offset.

Undang-Undang No. 12 Tahun 2010 Tentang Kepramukaan

Wilson, Nikki. 2009. Impact of Extracurricular Activities on Student. American Psychological Association Journal. Vol. 5 No. 4; April 2009. American Psychological Association, USA.

Wiyono, Bambang. Budi. 2007. Metodologi Penelitian: Pendekatan Kuantitatif, Kualitatif dan Action Research (Burhanudin, Ed). Malang: Rosindo Malang. 